\title{
Natural leukocyte interferon alpha (Alfaferone) combined with ribavirin in the treatment of patients with $\mathrm{HCV}$-related cirrhosis: our experience
}

\author{
D. Kozielewicz • D. Dybowska • W. Halota • \\ W. Dróżdż
}

Received: 19 July 2010/ Accepted: 9 June 2011/Published online: 8 July 2011

(c) The Author(s) 2011. This article is published with open access at Springerlink.com

\begin{abstract}
Background The aim of the study was to evaluate the efficacy and safety of combined treatment with natural leukocyte interferon alpha (Alfaferone) plus ribavirin in patients with HCV-related cirrhosis.

Patients and methods Twenty-three patients (15 women, 8 men) aged 17-68 years hospitalized in 2005-2008 were included in the study. Seventeen patients who qualified for treatment were Child-Pugh class A patients and 6 others were class B. Seventeen patients had genotype $1 \mathrm{~b}$ and 6 genotype $3 \mathrm{a}$ infection. Thirteen patients were naïve, retherapy concerned 8 patients, and in two cases the continuation of treatment had been stopped because of adverse events following the use of pegylated interferons. The treatment was continued for 48 weeks regardless of $\mathrm{HCV}$ genotype. Normalized AlAT activity $(<40 \mathrm{U} / \mathrm{l})$ was the measure of biochemical efficacy of the treatment, while virological efficacy was reflected by an undetectable viral load in plasma. Both measurements were conducted immediately after the end of treatment (EOT) and after a 6-month follow-up period (SVR). Therapeutic safety was evaluated by the monitoring of the adverse events of the treatment.
\end{abstract}

Results Abnormal AlAT levels prior to treatment were detected in 20/23 patients. During therapy normalized

D. Kozielewicz $(\bowtie) \cdot$ D. Dybowska · W. Halota

Dept. of Infectious Diseases and Hepatology, Collegium

Medicum, N. Copernicus University, 85-090 Bydgoszcz,

ul. Św.Floriana 12, Toruń, Poland

e-mail: d.kozielewicz@wsoz.pl

\section{W. Dróżdż}

Institute of Clinical Neuropsychology, Collegium Medicum,

N. Copernicus University, 85-094 Bydgoszcz,

ul. C.Skłodowskiej 9, Toruń, Poland levels were achieved in $50 \%$ of them, and after 6 months they were sustained in 9/20. EOT was achieved in 6/19 patients and SVR in 3 patients. Mild psychiatric disorders were the most frequently detected adverse events (12 patients). Thrombocytopenia and leucopenia existing prior to treatment did not intensify during the treatment. Severe adverse events caused by the drug resulted in the discontinuation of treatment in three patients (urinary tract infections, depression, myasthenia gravis), of whom two patients were Child-Pugh class A and one was class B. In one patient treatment was discontinued because of HCC. Conclusion Natural leukocyte interferon alpha is well tolerated by patients with HCV-related cirrhosis and coexisting thrombocytopenia and leucopenia.

Keywords Adverse events - Cirrhosis - Natural leukocyte interferon alpha Sustained virological response

\section{Introduction}

The combination of pegylated interferon and ribavirin is the current standard treatment for chronic HCV infections [1]. Other interferons may be administered when the pegylated interferon therapy is contraindicated or when adverse events of this treatment are present (e.g., cytopenia during the already initiated treatment). This is particularly important in patients with cirrhosis, where neutro- and thrombocytopenia are frequently observed [2]. In clinical practice these problems are considered a criterion disqualifying patients from treatment [1]. In such cases an attempt can be made to treat patients with natural leukocyte interferon alpha, a blend of different interferon types with complementary activity. As a consequence, interferon alpha is the first choice drug in the discussed cases. 
This paper presents our experience in the use of natural leukocyte interferon alpha (Alfaferone) combined with ribavirin in the treatment of patients with $\mathrm{HCV}$-related cirrhosis. This concerned naïve patients, re-therapy, and the continuation of previous treatment that had been discontinued because of adverse events.

\section{Materials and methods}

Twenty-three patients with HCV-related cirrhosis treated in the Department of Infectious Diseases and Hepatology in Bydgoszcz, Poland, in 2003-2008 were included in the study. This group comprised 15 women and 8 men aged 17-68 years (average 52 years). The average body mass of patients was $77.6 \mathrm{~kg}(57.5-114 \mathrm{~kg})$. Characteristics of the patients are presented in Table 1.

Hepatitis C virus RNA was detected based on the results of RT PCR tests. We analyzed the levels of baseline viremia and its kinetics in the course of therapy. We

Table 1 Characteristics of the patient population

\begin{tabular}{|c|c|}
\hline Sex (female/male) & $15 / 8$ \\
\hline Age (years) (average) & $17-68(52)$ \\
\hline \multicolumn{2}{|l|}{ Child-Pugh score } \\
\hline A & 17 \\
\hline B & 6 \\
\hline Weight (kg) (average) & $57.5-114(76)$ \\
\hline Duration of treatment (weeks) & 48 \\
\hline $\begin{array}{l}\text { First treatment with LeIFN } \\
\text { alpha }+\mathrm{RBV}\end{array}$ & 13 \\
\hline $\begin{array}{l}\text { Continuation with LeIFN alpha after } \\
\text { PegIFN } 2 a / 2 b\end{array}$ & 2 \\
\hline Retreatment with LeIFN alpha + RBV & 8 \\
\hline \multicolumn{2}{|l|}{ IFN preparation } \\
\hline rIFN $2 b$ & 1 \\
\hline $\mathrm{rIFN} 2 \mathrm{~b}+\mathrm{RBV}$ & 1 \\
\hline PegIFN 2a + RBV & 4 \\
\hline PegIFN 2b + RBV & 2 \\
\hline \multicolumn{2}{|l|}{ HCV genotype } \\
\hline $1 b$ & 17 \\
\hline $3 a$ & 6 \\
\hline $\begin{array}{l}\text { Pretreatment HCV RNA levels (IU/ml) } \\
\text { (average) }\end{array}$ & $\begin{array}{l}3.75 \times 10^{3}-1.92 \times 10^{7} \\
\left(3.33 \times 10^{6}\right)\end{array}$ \\
\hline \multicolumn{2}{|l|}{ Pretreatment AlAT levels (U/l) } \\
\hline 3 patients & Normal \\
\hline 20 patients & $50-408(150)$ \\
\hline EOT & 6 \\
\hline SVR & 3 \\
\hline
\end{tabular}

EOT end of treatment response, SVR sustained virological response, $r I F N 2 b$ recombinant interferon alpha $2 \mathrm{~b}$, LeIFN alpha natural leukocyte interferon alpha, $R B V$ ribavirin, PegIFN $2 a / 2 b$ pegylated interferon alpha $2 \mathrm{a} / 2 \mathrm{~b}$ detected 17 infections with genotype $1 \mathrm{~b} \mathrm{HCV}$ and 6 infections with genotype $3 \mathrm{a} \mathrm{HCV}$.

Cirrhosis was diagnosed based on generally accepted clinical, biochemical and histological criteria. Seventeen Child-Pugh class A patients and 6 Child-Pugh class B patients were qualified for the treatment. Classification into Child-Pugh class B was determined by elevated bilirubin levels of up to $2-3 \mathrm{mg} / \mathrm{dl}$ (3 patients), reduction of albumin levels down to $3.5-2.8 \mathrm{~g} / \mathrm{dl}$ (3 patients), prothrombin time elongation ( 6 patients), and/or ascites ( 3 patients). Patients with peritoneal fluids present were treated with diuretics until the condition was resolved. Twenty of 23 patients had increased activity of alanine aminotransferase (50-408 U/1, average level $150 \mathrm{U} / \mathrm{l})$. Five patients were diagnosed with esophageal varices, of whom two were treated with betablockers and three with endoscopic banding ligation.

Each patient who met the criteria for the therapy was monitored for hepatocellular carcinoma (HCC). Prior to treatment and every 3 months patients were examined by abdominal ultrasound scan, and the level of alpha-fetoprotein (AFP) in plasma was measured. When test results were uncertain, diagnostic methods were complemented with abdominal computer tomography (CT). Qualification of patients for therapy included repeated psychiatric consultation during the course of therapy.

The discussed group of patients consisted of 13 naïve patients and 8 patients who were being treated because of ineffective previous treatment. In two cases the treatment was a continuation of previous treatment with pegylated interferon that had been discontinued because of adverse events of the drug treatment (leucopenia with coexisting hyperthyreosis and thrombocytopenia).

Alfaferone (Alfaferone ${ }^{\circledR}$; ALFA WASSERMANN, Bologna, Italy) was used in a dose of three million units, three times a week, by subcutaneous injection. Ribavirin (Rebetol ${ }^{\circledR}$; Schering-Plough, Kenilworth, NJ) was administered orally in a daily dose of 800-1,200 mg, depending on body mass. Five of 23 patients were initially treated with ribavirin doses lower than that suggested by their body mass. This was due to starting hemoglobin levels of $10-11 \mathrm{~g} / \mathrm{dl}$ and was dictated by patient safety considerations. Three out of those five patients were classified into Child-Pugh class A. The treatment was continued for 48 weeks regardless of HCV genotype. Therapeutic efficacy was assessed based on the level of HCV viremia directly after the end of treatment (EOT) and after a further 24 weeks sustained virological response (SVR) and subsidence of the previous biochemical activity of the disease.

Adverse events associated with the treatment were analyzed based on clinical observations and laboratory tests conducted at 2-week intervals. The effect of Alfaferone on thrombocytopenia and leukopenia detected prior to treatment was analyzed. 
AFP level was measured with the chemiluminescence method using the LIAISON AFP test from DiaSorin (reference values up to $5.5 \mathrm{IU} / \mathrm{ml}$ ) (Humor Diagnostica, South Africa).

The activity of alanine aminotransferase (AlAT) was measured using the ICFF method without pyridoxal phosphate at a temperature of $37^{\circ} \mathrm{C}$ using a test kit from Roche and the Cobas Integra analyzer. Correct levels were below $40 \mathrm{U} / \mathrm{l}$, regardless of sex.

HCV RNA was detected with RT PCR at the method's linearity of $43-6.9 \times 10^{7} \mathrm{IU} / \mathrm{ml}$ using the COBAS AmpliPrep/COBAS TaqMan HCV test (HCMCAP) reagent from Roche Diagnostic (Indianapolis, IN), while the HCV genotype was detected by hybridization with Linear Array HCV Genotyping Test (LA HCV GT) reagents from Roche.

Platelet and leukocyte levels were measured with the conductometric method on a Sysmex K-4500 analyzer (Sysmex Corp., Japan), and the ratio of leukocyte subpopulations was measured based on blood smear in a microscopic specimen stained using the May-Grünvald, Giemsa method.

\section{Results}

Nineteen of 23 patients successfully completed the planned treatment. EOT was achieved in six patients (five ChildPugh class A patients and one Child-Pugh class B patient). Five patients were infected with a genotype $1 \mathrm{~b}$ virus and one patient with genotype 3a. Three patients in which a virological response was achieved at the EOT were naïve patients. Another one patient was in a re-treatment group, and in two patients Alfaferone and ribavirin therapy was the continuation of previous treatment with pegylated interferon. SVR was achieved in three patients (all Child-
Pugh class A). All patients were infected with genotype $1 \mathrm{~b}$. SVR was achieved in $1 / 13$ naïve patients and in two patients where Alfaferone was used instead of pegylated interferon.

AlAT was normalized during the treatment in 10 out of 20 patients who demonstrated elevated biochemical activity prior to treatment, and in 9 cases it was sustained during a 6-month follow-up period.

Treatment was discontinued in four patients. In three cases this was due to adverse events caused by the drug, and in one patient it was due to diagnosed HCC. The patient with HCC was sent to the transplantation ward where qualification to liver transplant was started. Adverse events disqualifying patients from further treatment included intensified depression, myasthenia gravis and urinary tract infections that led to decompensation of hepatic function in one Child-Pugh class B patient. Other patients were qualified to class A.

Other most frequently recorded adverse events were psychiatric disorders, reflected by impaired mental function, sleep disorders, mood swings, neurasthenia, and depressive syndromes. Two patients were diagnosed with infections: one patient had recurrent labial herpes, and the other had a urinary tract infection. Adverse events frequently coexisted. Most adverse events were observed in Child-Pugh class A patients. Stable angina pectoris was diagnosed in one Child-Pugh class B patient, and depressive disorders were diagnosed in another two Child-Pugh class B patients.

Adverse events and the reasons for premature discontinuation of natural leukocyte interferon alpha treatment are presented in Table 2.

Eight of 23 patients had leucopenia befor Alfaferone and ribavirin treatment. None of the five patients with absolute neutrophil counts below $1,500 / \mathrm{mm}^{3}$ required a reduced dose of Alfaferone for longer than 2 weeks (Table 3).
Table 2 Adverse events and reasons for premature discontinuation of treatment with natural leukocyte interferon alpha

\begin{tabular}{lll}
\hline $\begin{array}{l}\text { Adverse events caused } \\
\text { by Alfaferone }\end{array}$ & $\begin{array}{l}\text { Total number of cases/ } \\
\text { Child-Pugh score (A/B) }\end{array}$ & $\begin{array}{l}\text { Number of prematurely } \\
\text { discontinued treatments } \\
\text { (Child-Pugh score) }\end{array}$ \\
\hline Psychiatric disorders & $12 /(10 / 2)$ & $1(\mathrm{~A})$ \\
General weakness & $7 /(7 / 0)$ & - \\
Flu-like symptoms & $3 /(2 / 1)$ & - \\
Skin lesions & $3 /(3 / 0)$ & - \\
Infections & $3 /(2 / 1)$ & $1(\mathrm{~B})$ \\
Visual disorders & $1 /(0 / 1)$ & - \\
Angina pectoris, stable & $1 /(0 / 1)$ & - \\
Hyperthyroidism & $1 /(1 / 0)$ & - \\
Hair loss & $1 /(1 / 0)$ & - \\
Myasthenia gravis & $1 /(1 / 0)$ & $1(\mathrm{~A})$ \\
HCC & $1 /(1 / 0)$ & 1 (A) \\
\hline
\end{tabular}


Table 3 The effect of Alfaferone on leucopenia existing prior to treatment

${ }^{a}$ Leukocytes-normal range $4-10 \times 10^{3} / \mu 1$

Table 4 The effect of Alfaferone on platelets level existing prior to treatment

\begin{tabular}{|c|c|c|c|}
\hline $\begin{array}{l}\text { Patient } \\
\text { no. }\end{array}$ & $\begin{array}{l}\text { Initial platelet } \\
\text { levels }\left(\times 10^{3} / \mu \mathrm{l}\right)^{\mathrm{a}}\end{array}$ & $\begin{array}{l}\text { Minimum } \\
\text { platelet levels } \\
\text { during treatment } \\
\left(\times 10^{3} / \mu \mathrm{l}\right)\end{array}$ & $\begin{array}{l}\text { Platelet levels } \\
\text { in } 48 \text { th week } \\
\text { of treatment } \\
\left(\times 10^{3} / \mu 1\right)\end{array}$ \\
\hline 1 & 54 & 54 & 82 \\
\hline 2 & 27 & 27 & 51 \\
\hline 3 & 62 & 38 & 57 \\
\hline 4 & 57 & 49 & 59 \\
\hline 5 & 74 & 74 & 101 \\
\hline 6 & 53 & - & - \\
\hline 7 & 44 & 44 & 55 \\
\hline 8 & 46 & 32 & 30 \\
\hline 9 & 53 & 53 & 280 \\
\hline 10 & 68 & 50 & 50 \\
\hline 11 & 65 & 64 & 82 \\
\hline 12 & 51 & 42 & 51 \\
\hline 13 & 20 & 17 & 18 \\
\hline 14 & 29 & 24 & 34 \\
\hline 15 & 86 & 38 & 51 \\
\hline 16 & 65 & 48 & 69 \\
\hline 17 & 19 & 17 & 56 \\
\hline 18 & 53 & 139 & 280 \\
\hline 19 & 132 & 154 & 219 \\
\hline 20 & 208 & 142 & 169 \\
\hline 21 & 100 & 75 & 94 \\
\hline 22 & 126 & 102 & 151 \\
\hline 23 & 161 & 85 & 158 \\
\hline
\end{tabular}

a Platelets-normal range $150-350 \times 10^{3} / \mu 1$

No significant reduction in platelet level was recorded in 17 patients with thrombocytopenia below $90,000 / \mu 1$, which would have required modification of interferon dosage (Table 4).

During treatment the dosage of ribavirin was reduced in ten patients because of decreased hemoglobin levels below
$10 \mathrm{~g} / \mathrm{dl}$ and/or clinical symptoms of anemia, decreased tolerance of physical effort, or vertigo.

\section{Discussion}

Alfaferone is highly purified interferon alpha containing 18 interferon subtypes derived from human leukocytes [3]. A few research papers on the use of Alfaferone in the treatment of patients with HCV-related cirrhosis have been published so far [4-7].

Patients with cirrhosis are classified as "difficult to treat." Aghemo et al. in their study emphasized that treatment based on pegylated interferon alpha $2 b$ in patients with cirrhosis infected with genotypes 1, 3, and 4 HCV yielded significantly less SVR than in patients without cirrhosis (genotypes 1 and 4: 17 vs. 36\%; genotype 3: 33 vs. 79\%). Relapses were observed more frequently in cirrhotic patients (genotypes 1 and 4: 55 vs. 31\%; genotype 3: 61 vs. 12\%) [8]. Our study confirmed these findings as SVR was achieved in three patients. In addition, factors responsible for treatment failure particularly include high baseline viremia $(>800,000 \mathrm{IU} / \mathrm{ml})$, body mass over $75 \mathrm{~kg}$, age over 40 years during infection, HIV/HCV coinfection, and previous ineffective treatment [9-11]. These factors, except for HIV infection, frequently coincided in the studied group of patients. Treatment efficacy also depends on ribavirin dose [1, 12]. Some patients from the study group required reduced doses of ribavirin, which may have affected the treatment outcomes.

Alfaferone was tolerated well by patients with hematological disorders, and patients with contraindications against using other interferon types were treated (thrombocytopenia $<90 \times 10^{3} / \mu \mathrm{l}$, neutropenia $\left.<1,500 / \mathrm{mm}^{3}\right)$. Thrombocytopenia did not intensify significantly during treatment. Even in patients with platelet levels below $30,000 / \mu 1$, no clinical symptoms of thrombocytopenia were detected, and in none of them was treatment discontinued 
for this reason. These findings conform with reports by other authors and with our previous studies [5, 13-17].

Psychiatric disorders observed during the treatment based on natural leukocyte interferon alpha were mild, except for in one patient, and were successfully managed by psychotherapeutic and pharmacological methods. Infections were not diagnosed in patients with neutropenia.

In the patient who developed $\mathrm{HCC}, \mathrm{HCV}$ viremia was never undetectable during the treatment. Similar observations were made by Ferrara et al. [18]. Standard therapy with pegylated interferon plus ribavirin is recommended only in Child-Pugh class A patients [1]. Alfaferone can also be used, as demonstrated by our own experience, in class B patients. We did not observe differences in the frequency of adverse events or lower tolerance to treatment between Child-Pugh patients class B and class A. Patients with HCV-related cirrhosis are potential candidates for liver transplant, and for this reason antiviral treatment should be applied prior to surgical procedures [1]. In patients with liver cirrhosis if there is no option for optimal therapy with pegylated interferon plus ribavirin because of cytopenias, for example, the use of natural leukocyte interferon alpha plus ribavirin should be considered.

\section{Conclusions}

1. Although the data are very limited (23 patients), treatment with natural leukocyte interferon alpha (Alfaferone) plus ribavirin in patients with $\mathrm{HCV}$-related cirrhosis seems to be safe.

2. Alfaferone administered in patients with thrombocytopenia and neutropenia did not exacerbate these hematological disorders and caused no threat to life.

3. Alfaferone was well tolerated by both Child-Pugh class A and class B patients.

\section{Conflict of interest None.}

Open Access This article is distributed under the terms of the Creative Commons Attribution Noncommercial License which permits any noncommercial use, distribution, and reproduction in any medium, provided the original author(s) and source are credited.

\section{References}

1. Ghany MG, Strader DB, Thomas DL, et al. Diagnosis, management and treatment of hepatitis $\mathrm{C}$ : an update. Hepatology. 2009;49:1335-74.
2. Dusheiko G. Thrombopoietin agonists for the treatment of thrombocytopenia in liver disease and hepatitis C. Clin Liver Dis. 2009;13:487-501.

3. Osterborg A. Patients treated with natural (leukocyte-derived) interferon-alpha do not develop IFN antibodies (letter). Eur J Haematol. 1991;47:234.

4. Łapiński TW, Dąbrowska MM, Flisiak R. Leukocytarny interferon naturalny alfa (IFN- $\alpha$ N3) w leczeniu chorych przewlekle zakażonych HCV. Zakażenia. 2008;1:63-7.

5. Cacopardo B, Nunnari G, Benanti F, et al. Leukocyte interferon alpha early retreatment for Child A HCV genotype 1 b-infected cirrhotics intolerant to pegylated interferons. Infection. 2009;37:210-5.

6. Adinolfi LE, Durante-Mangoni E, Salzillo M, et al. Leukocyte interferon-alpha and ribavirin for treatment of chronic hepatitis $\mathrm{C}$ patients intolerant to pegylated-interferon. Intern Emerg Med. 2009;4:485-90.

7. Napoli N, Giannelli G, Parisi CV, et al. Predictive value of early virological response to treatment with different interferon-based regimens plus ribavirin in patients with chronic hepatitis $\mathrm{C}$. New Microbiol. 2005;28:13-21.

8. Aghemo A, Rumi M.G, Monico S, et al. Genotype dependent pattern of peginterferon alfa-2b/ribavirin treatment failure in hepatitis $\mathrm{C}$ virus infected patients with cirrhosis: a single center study of 471 naïve patients. J Hepatol. 2008;48:287.

9. Poynard T, Ratzin V, Charlotte F, et al. Rates and risk factors of liver fibrosis progression in patients with chronic hepatitis C. J Hepatol. 2001;43:730-9.

10. Zeuzem S, Hultcrantz R, Bourliere M, et al. Peginterferon alpha$2 \mathrm{~b}$ plus ribavirin for treatment of chronic hepatitis $\mathrm{C}$ in previously untreated patients infected with HCV genotypes 2 or 3 . J Hepatol. 2004;40:993-9.

11. Righi E, Beltrame A, Bassetti M, et al. Therapeutical aspects and outcome of HIV/HCV coinfected patients treated with pegylated interferon plus ribavirin in an Italian cohort. Infection. 2008;36:358-61.

12. Morello J, Rodriguez-Novoa S, Jiménez-Nácher I, et al. Usefulness of monitoring ribavirin plasma concentrations to improve treatment response in patient with chronic hepatitis C. J Antimicrob Chemother. 2008;62:1174-80.

13. Cacopardo B, Benanti F, Brancati G, et al. Leukocyte interferonalpha retreatment for chronic hepatitis $\mathrm{C}$ patients previously intolerant to other interferons. J Viral Hepat. 1998;5(5):333-9.

14. Colombutto P, Oliveri F, Leandro G, et al. Platelet and white blood cell counts during therapy with different types of alpha interferon in patients with chronic viral hepatitis. Ital J Gastoenterol Hepatol. 1997;29:441-7.

15. Toccaceli F, Roseti S, Scuderi M, et al. Leukocyte and platelet lowering by some interferon types during viral hepatitis treatment. Hepatogastroenterology. 1998;45:1748-52.

16. Dybowska D, Halota W. Zastosowanie interferonu naturalnego (Alfaferone) w praktyce klinicznej-doświadczenia własne. Przegl Epidemiol. 2007;61:17-22.

17. Benci A, Caremani M, Tacconi D, et al. Thrombocytopenia in patients with HCV-positive chronic hepatitis: efficacy of leukocyte interferon alpha treatment. Int J Clin Pract. 2003;57:16-9.

18. Ferrara F, Baldo V, Rosa Rizzotto E, et al. Interferon alpha $2 b$ plus ribavirin for naïve patients with $\mathrm{HCV}$-related cirrhosis. J Hepatol. 2007;46:223. 